Published as: Nuttens, T., Stal, C., De Backer, H., Schotte, K., Van Bogaert, P., Detry, P., De Wulf, A., 2014. Terrestrial laser scanning as a key element in the integrated monitoring of tidal influences on a twin-tube concrete tunnel. The Photogrammetric Record, Vol. 29 (148), pp. 402-416, December 2014, DOI: $10.1111 /$ phor.12080.

\title{
TERRESTRIAL LASER SCANNING AS A KEY ELEMENT IN THE INTEGRATED MONITORING OF TIDAL INFLUENCES ON A TWIN-TUBE CONCRETE TUNNEL
}

TIMOTHY NuTTENS (Timothy.Nuttens@gmail.com)

CORNELIS STAL (Cornelis.Stal@UGent.be),

Department of Geography, Ghent University, Belgium

HANS DE BACKER (Hans.DeBacker@UGent.be)

KEN SCHOTTE (Ken.Schotte@UGent.be)

PHILIPPE VAN BOGAERT (Philippe.VanBogaert@UGent.be),

Department of Civil Engineering, Ghent University, Belgium

PIERRE DETRY (Pierre.Detry@ tucrail.be)

Lines \& Environment Unit, Topografie cel, TUC RAIL, Brussels, Belgium

AlAIN DE Wulf (Alain.DeWulf@UGent.be)

Department of Geography, Ghent University, Belgium

Abstract

In 2012, for the first time in Belgium, integrated monitoring was carried out to assess the deformations of a twin-tube tunnel below the River Scheldt in Antwerp under the influence of estuarine tides. Levelling measurements during a tide cycle showed a variation in the height of levelling bolts of up to $10 \mathrm{~mm}$ between low and high tide. Simultaneous strain-gauge measurements also showed a significant difference in strains. A deformation of the tunnel section during each twice-daily tide cycle, resulting in an eccentric 'egg' or 'pumpkin' shape, could hold large risks for the strength and durability of the tunnel structure. However, laser scanning results showed that there were no significant 
deformations of the tunnel's shape during the tide cycle. The laser scanning measurements resulted in a more thorough view of the deformation pattern which was much needed and improved the long-term risk assessment of the tunnel.

KEYWORDS: laser scanning, tide cycle, deformation monitoring, levelling, tunnel construction

\section{INTRODUCTION}

A THOROUGH AND CONTINUOUS RISK ASSESSMENT of large infrastructure objects such as hydro-electric dams, bridges or concrete beams is indispensable to guarantee the safety of related construction projects. Various monitoring instruments and methodologies can be applied, depending on the required accuracy, the type and dimensions of the structure, the field conditions and so on. A wide variety of continuous monitoring techniques is available, such as strain measurements or the automated sequential measurement of reference points with total station or global navigation satellite system (GNSS) measurements (Fujino and Siringoringo, 2011; Khoo et al., 2010; Psimoulis and Stiros, 2007; Schotte et al., 2013a). In many projects, discontinuous monitoring measurements are also scheduled during which the entire construction or a limited number of reference points of the structure are measured at specific moments in time. Total stations, GNSS, photogrammetry or laser scanning are frequently used for these measurements (Alba et al., 2006; Bertacchini et al., 2010; Chounta and Ioannidis, 2012; Needham and Dash, 2012; Peeters et al., 2009; Roca-Pardiñas et al., 2013; Zogg and Ingensand, 2008). An extensive and systematic monitoring of large projects is not only compulsory during construction but also throughout the subsequent years; systematic monitoring can detect possible risks at an early stage. Such a risk assessment has to be based on accurate up-to-date data, clear information, rapid results and conclusions, requiring specific monitoring techniques to meet these demands (Caballero et al., 2007; Lerma Garcia et al., 2008).

The current research investigates the use of laser scanning to assess complex tunnel deformations. More specifically, a case study of a tunnel running below a tidal river is discussed. In this study integrated monitoring, combining levelling and strain gauge measurements with highly accurate laser scanning measurements, was set up to gain greater insight into the tunnel's deformations under tidal influences and to assess the added value of laser scanning for monitoring projects.

During recent years, (terrestrial) laser scanning has been applied as a technique to measure large installations and to meet specific monitoring demands. The measurement speed, high achievable accuracy and the possibility of obtaining a detailed and complete 3D image of complex objects, are important advantages contributing to its growth (Han et al., 2013a; Lichti and Chow, 2013; Remondino et al., 2011). While classical surveying measurements with a total station offer higher single-point accuracy, they are limited in the number of points that can be measured in a specified time frame (Alba et al., 2006). To cover a denser point grid, digital photogrammetry can be used as an alternative recording technique. Subsequent 3D models can be used to detect any structural deformations with time. However, 
additional measurements with a total station or GNSS are often required and the measurement conditions on site usually do not meet the requirements for accurate photogrammetric results, such as sufficient lighting or contrast on the object's surface. Laser scanning is an active measurement technique and consequently deals with many of the aforementioned restrictions, making accurate measurements of a dense point grid possible in difficult field conditions and within a limited time frame, even from a distance of up to several hundreds of metres (Lichti et al., 2000; Pfeifer and Briese, 2007; Rönnholm et al., 2009; Thomas and Isaacs, 2011). Currently, terrestrial laser scanning is successfully being used for high-accuracy deformation measurements of tunnels, either as a part of a long-term monitoring programme or during the construction phase (Argüelles-Fraga et al., 2013; van Gosliga et al., 2006; Han et al., 2013b; Lam, 2006; Lindenbergh et al., 2005; Nuttens et al., 2014b; Pejić, 2013; Yoon et al., 2009). These research examples clearly indicate the suitability of laser scanning for accurate 3D monitoring of large structures (Nuttens et al., 2014a).

However, as will be discussed in this paper, a more advanced challenge is to combine this highly accurate laser scanning methodology with other applied monitoring techniques to assess difficult or critical deformation patterns. The combination of simultaneous levelling measurements, strain-gauge registrations and laser-scanning measurements in the Belgian tunnelling project discussed in this research is an important step forward in the awareness of the relevance of an integrated monitoring strategy for large infrastructural projects and of the relevance to include laser scanning measurements to obtain a more thorough view of the deformations. Laser scanning not only offers a full 3D view of the tunnel construction, but an optimal use of the data also allows the detection of other aspects of the tunnel's deformation, resulting in a better judgement of the risks of the deformations.

The following sections will discuss the tunnel monitoring project and the tidal influences on the tunnel construction in more detail. Subsequently, the levelling and strain gauge measurements will be commented on, followed by a more detailed explanation of the laser-scanning measurements. The results of the deformation monitoring and the important contribution of the laser scanning measurements to the conclusions about the deformation pattern are then explained. This paper ends with a discussion about the integration of the various results and the tidal movements of the tunnel structure, with final conclusions concerning the use of laser scanning as an important monitoring technique for this kind of application.

\section{LIEFKENSHOEK RAIL LINK PROJECT}

The 'Liefkenshoek Rail Link' project (2010-2014) establishes a new railway connection for freight traffic between the left and right banks of the River Scheldt in the Port of Antwerp (Belgium). This new railway connection has a total length of approximately $16 \mathrm{~km}$, of which $6 \mathrm{~km}$ consists of two twin tunnels ('Tunnel North' and 'Tunnel South'), constructed in 2010-2011 by two shield-driven tunnel boring machines (TBMs) using the mixshield method (van Bogaert, 2009). The first use of this new railway connection is in December 2014. This newly bored tunnel complex crosses two waterways (River Scheldt and Canal Dock/Port Canal), the soil cover above the tunnel being rather shallow (3 to $10 \mathrm{~m}$ ) (Fig. 1). 


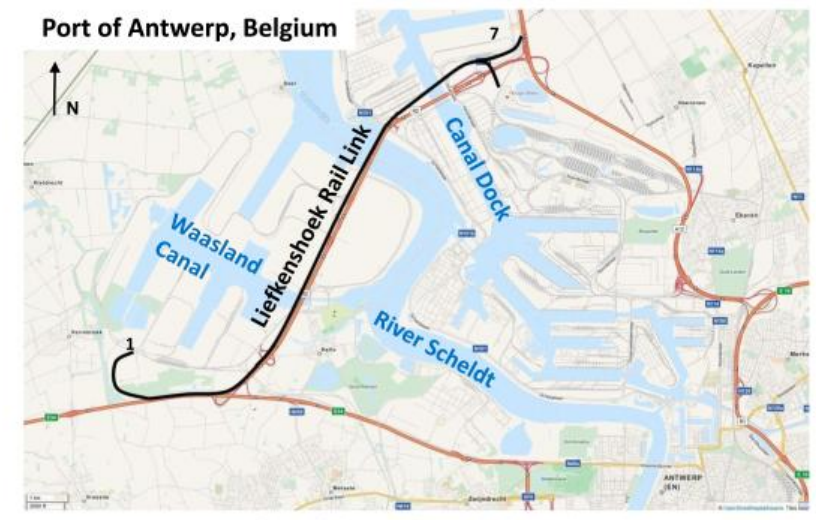

Profile of the Liefkenshoek Rail Link

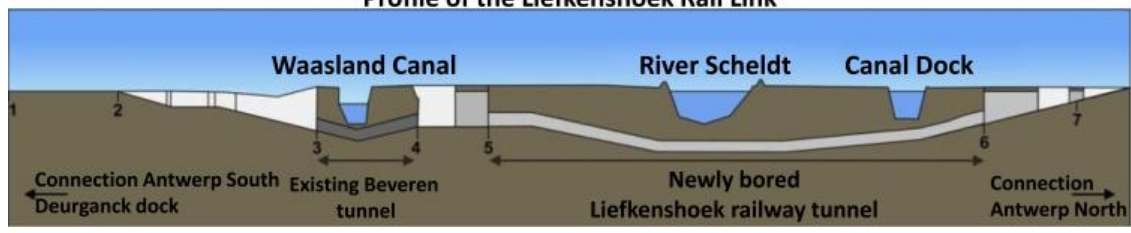

FIG. 1. Upper: overview of the new 'Liefkenshoek Rail Link' in the Port of Antwerp between the left and right banks of the River Scheldt. Lower: longitudinal profile illustrating the newly-bored tunnel's location under the River Scheldt and the Canal Dock. (Based on openstreetmap.org; bam.nl; maps.google.be, October 2, 2013.)

The geological characteristics of the tunnel-boring site are of a variable nature. The soil stratification has a generally downward slope from west to east. The left bank of the River Scheldt (west) consists of sandy layers until a depth of 4 to 6 metres; below these layers quaternary soft clay and peats appear. This clay layer does not occur on the right bank of the river (east). Deeper, one finds a layer of the tertiary era with a maximum thickness of 6 metres, containing silt and a mixture of fine sand and clay. Below this, a $6 \mathrm{~m}$ tertiary sand stratum, containing of silt and clay particles, is found; this is followed by 9 to $14 \mathrm{~m}$ thick tertiary fine sands, containing clay as well as glauconite. At greater depths the soil consists of Boom clay, which is an overconsolidated type of saturated soil, acting as an impermeable layer. The tunnel mostly runs through the tertiary sands, but at its deepest point (below the River Scheldt) it also runs partly through the Boom clay.

The two newly-bored tunnels have an internal diameter of $7.300 \mathrm{~m}$ each, the concrete tunnel segments having a thickness of $0.400 \mathrm{~m}$. The tunnel is composed of a series of tunnel rings; the length of each tunnel ring is $1.800 \mathrm{~m}$, each ring consisting of seven concrete segments and one smaller key stone (TUC Rail, 2010) (Fig. 2). During the general monitoring programme, in the period from tunnel-ring assembly 
until approximately three months after construction, 14 tunnel sections in each tunnel tube were selected for monitoring. Seven instants (epochs) were defined on which the selected tunnel sections had to be measured with laser scanning: the 'reference measurement' immediately after construction of the tunnel section; a measurement every week during the first month after installation ('control measurements 1 to 4') and measurements two and three months after installation ('control measurement 5 and 6'). The determined cross-section measurements were compared with the design shape, the reference measurement and the previous control measurement of that tunnel section.

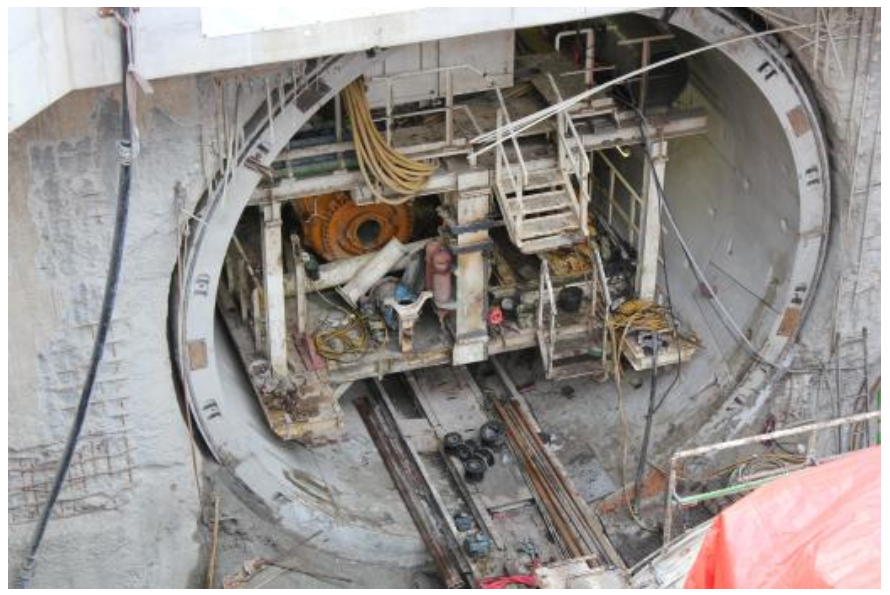

FIG. 2. A constructed tunnel ring at the end of one of the tunnel tubes. Each ring is $1.8 \mathrm{~m}$ long and consists of seven concrete segments and one smaller key stone

\section{TIDAL INFLUENCE ON THE TUNNEL CONSTRUCTION}

The River Scheldt has a direct connection with the North Sea and is therefore affected by the tidal water level variation in the North Sea. Twice a day, the River Scheldt reaches its lowest and highest water levels, with an average difference in water level of about $5 \cdot 5$ to 6 metres. Water level heights are measured relative to the Belgian height datum TAW (Tweede Algemene Waterpassing) (Fig. 3). This difference in water level between ebb and flood can increase with an additional $2 \mathrm{~m}$ during spring tides. Considering the shallow soil cover above the tunnel at the crossing with the River Scheldt ( 3 to $10 \mathrm{~m}$ ); the continuous variation in water level and water pressure had to be taken into account during the drilling work of both tunnel tubes, as well as for the maintenance of the structure. Moreover, as recent levelling measurements at the final stage of the works have shown, the influence of the variable water pressure still continues. 


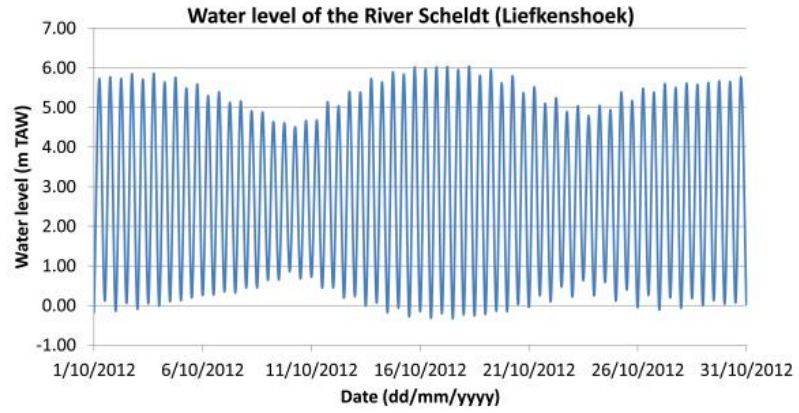

Fig. 3. Water level of the River Scheldt at Liefkenshoek during October 2012 .

TAW is the Belgian height datum. Data source: Hydrological Information Centre (Flanders).

For the levelling measurements during the construction period of the tunnel tubes, specially installed levelling bolts were measured. Measuring these bolts at different moments in time showed variations up to $10 \mathrm{~mm}$ in height between the various measurement sessions for several bolts below the River Scheldt. After extensive investigation of several levelling measurement series, a relation was found between the change in level of the levelling bolts and the tidal variations of the River Scheldt.

To further investigate this relationship between the measured elevations of the levelling bolts, the water-level variations and the influence of these variations on the whole surface of the tunnel rings, integrated monitoring was carried out. The latter combined levelling measurements with the strain and laser scanning measurement methodologies from the construction phase of the tunnel project. By measuring one specific tunnel ring below the River Scheldt during one day with simultaneous laser scan measurements, strain registrations and levelling measurements, an extensive image of the influence of the water level variations on the tunnel structure could be obtained. The combination of these three techniques and their respective results can confirm or exclude some deformation patterns and their causes, leading to an accurate and thorough knowledge of the deformations of the tunnel rings and their possible long-term consequences.

\section{INTEGRATED MONITORING}

\section{Levelling Measurements}

To obtain sufficient data to monitor the influence of the continuously changing water level, the integrated measurements were organised for 31st October 2012. Measurements were scheduled between 9:00 and 18:30, encompassing the situation at low tide (approximately 11:00) and high tide (approximately 16:10) of the River Scheldt.

The first part of the monitoring programme consisted of levelling measurements, performed hourly in one of the tunnel tubes (Tunnel South) by using a Leica DNA10 digital levelling instrument, with a specification of $0.9 \mathrm{~mm}$ standard deviation on height differences per $1 \mathrm{~km}$ with the use of an invar staff. Because of the limited time 
frame between the successive measurement series, a fixed reference point beyond the tidal influence of the river was selected as the starting point for the levelling measurements, instead of the beginning or end point of the tunnel tube. From this point (Ring 1100), located $720 \mathrm{~m}$ away from the monitored tunnel section, a two-way measurement was performed. The assumption of Ring 1100 being a stable reference point was confirmed by evaluating the measurement results, which showed that the height values of this point remained unchanged during the successive measurement series. Moreover, during previous levelling measurements along the tunnel's longitudinal profile, the levelling bolt at Ring 1100 also showed no tidal variations. Every fifty rings, levelling bolts were measured until the monitored tunnel section in the middle of the River Scheldt in Tunnel South was reached. The registered variations in height of up to $10 \mathrm{~mm}$ at the ring below the River Scheldt are much larger than the achievable accuracy with the levelling instrument as mentioned above, so an external cause is clearly present.

During the time frame of the monitoring, eight levelling measurement series could be performed and the results of these measurements are presented in Fig. 4. The graph in Fig, 4 is limited to between ring numbers 1250 and 1500 as this area is subject to the largest differences between low and high tide. Including the ring numbers 1100 to 1250 would significantly increase the range needed on the $\mathrm{Y}$ axis, reducing the graph's readability, without contributing to an understanding of the tidal influences on the levelling measurements.

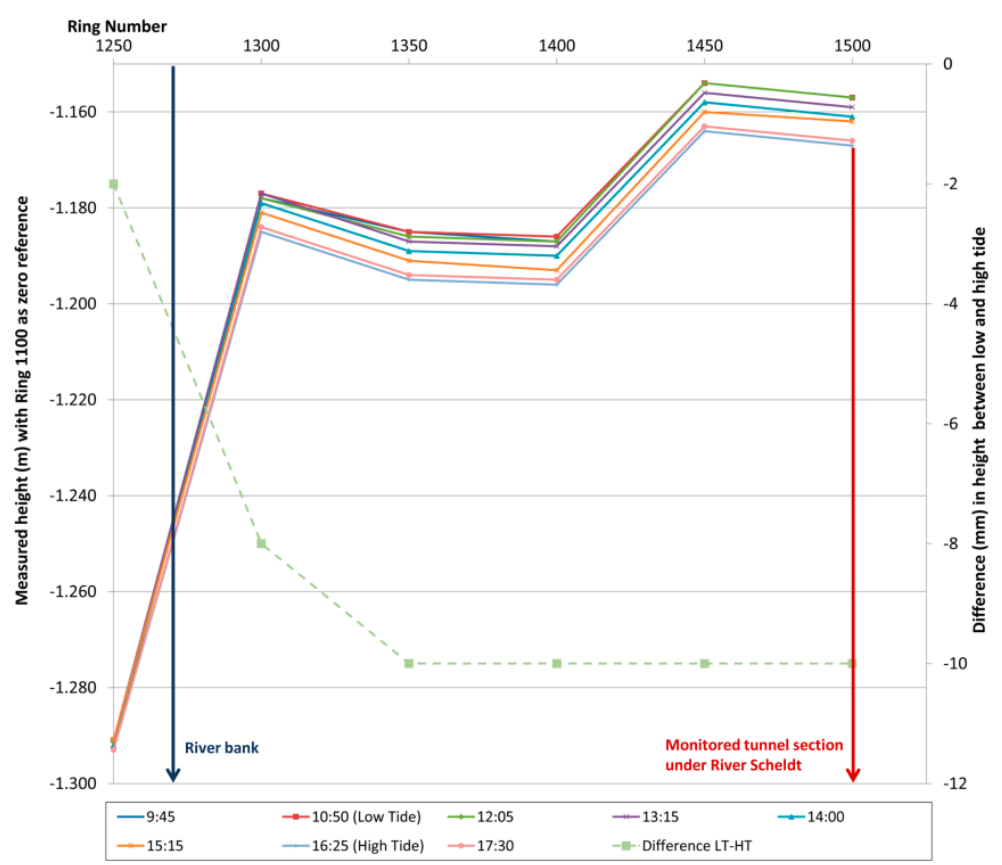


FIG. 4. Measured heights of the levelling bolts during the different measurement series (m) (left ordinate) and the differences between low and high tide (mm) (right ordinate). Ring numbers 1250 to 1500 form the absciss.

Fig. 4 clearly shows a variation in the height of the bolts below the River Scheldt between the series of measurements and thus between the different tide levels. The variation increases towards the deepest area below the River Scheldt, until the centre of the river is reached (Ring 1500). Moreover, the absolute height values of the monitored bolts wane between low and high tide and increase again after the high tide has passed, indicating the largest pressure on the tunnel structure is at high tide. The pecked line in Fig. 4 and the right ordinate (vertical axis) indicate the difference in height value between low and high tide for every measured levelling bolt. At ring 1250 , the difference between low and high tide produces a maximum bolt height difference of $2 \mathrm{~mm}$, whereas this difference at ring 1300 has already reached $8 \mathrm{~mm}$. After ring 1300 this difference slowly increases to a maximum difference of $10 \mathrm{~mm}$ at ring 1500 under the centre of the River Scheldt. This shows that the largest jump in difference between low and high tide can be located between ring number 1250 and 1300 , corresponding to the transition between the left river bank and the River Scheldt itself.

\section{Strain-Gauge Measurements}

Simultaneously with the levelling measurements, the integrated monitoring used strain-gauge measurements to detect the influences of the various loading conditions on the concrete segments of the tunnel rings (Fig. 5). During the tunnel construction phase, eight tunnel sections over the whole length of each tunnel tube were equipped with those strain gauges, including the selected tunnel ring below the River Scheldt. Because this part of the integrated monitoring is not the main topic of this paper, more information about the location of the strain gauges, together with the installation procedure and results of the monitoring during the construction phase, can be found in Schotte et al. (2013a).
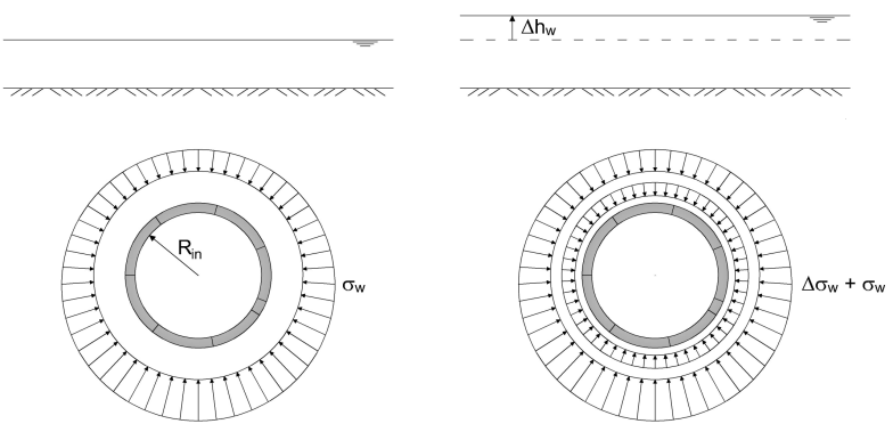

FIG. 5. Assumptions on radial-stress variation of the tunnel structure caused by the tidal changes in water level (Schotte et al., 2013b). 
The strain measurements during the integrated monitoring show an increase of the strains at low tide, indicating a general decrease of compression of the tunnel rings (Fig. 6). Between low tide and high tide, the growing water pressure above the tunnel section causes a larger compression of the tunnel rings as shown in the strain recordings. The continuous registration of those strains during the tide cycle also illustrates that there is no delay between the variation of the water level and the strain responses due to the ground cover above the tunnel (Schotte et al., 2014).

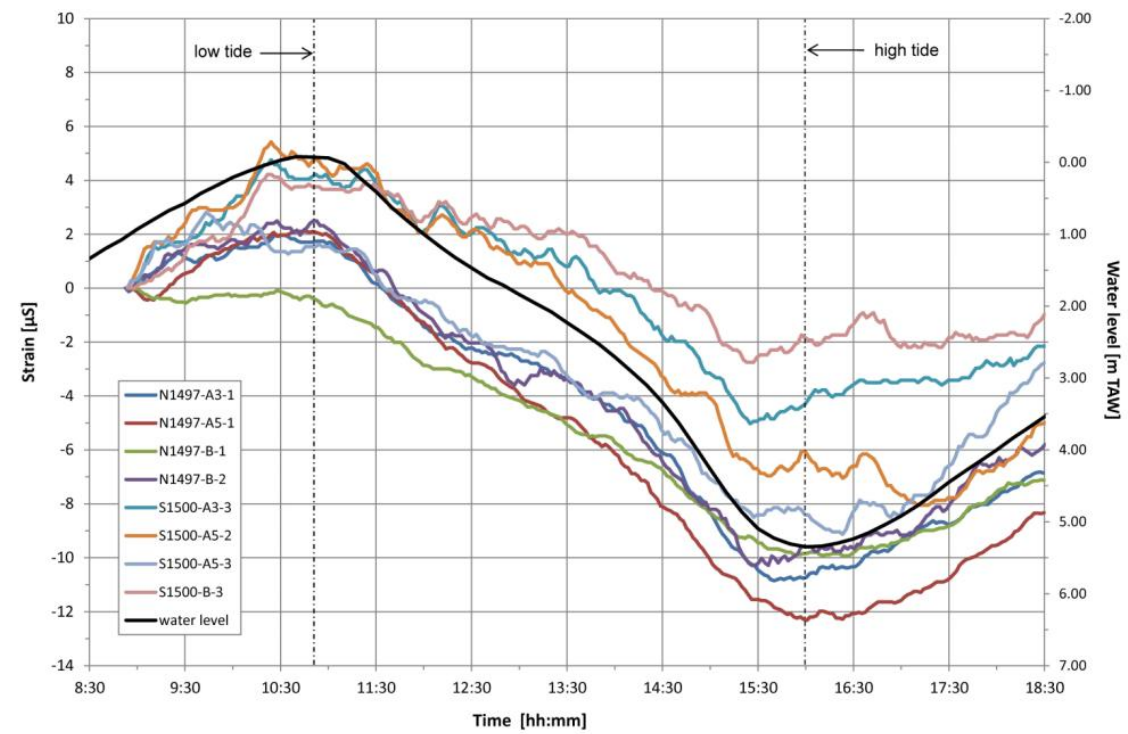

FIG. 6. Strain recordings in Tunnel North and Tunnel South during the integrated monitoring during 31st October 2012 (Schotte et al., 2014).

\section{Laser-Scan Measurements}

The third part of the monitoring consisted of laser scanning a tunnel section below the River Scheldt in both tunnel tubes; this was done every hour and, additionally, on the specific low and high tide moments. Following the developed measurement methodology as described in Nuttens et al. (2014b), a Leica HDS6100 phase-based laser scanner was set up on a tripod in the middle of the tunnel section, measuring the tunnel surface with an average point density of $4 \mathrm{~mm}$ from a distance of $6 \mathrm{~m}$. The first steps in the processing of the point clouds were removing the points that were not located on the concrete tunnel surface and the computation of a best-fit cylinder with 'free' diameter on this filtered point cloud. A cross section through the 3D triangulated surface of the tunnel section was then determined. This cross section was defined perpendicular to the tunnel's longitudinal axis and its exact intersection on the tunnel surface was fixed by the 'master' target, one of the targets attached to the tunnel surface for registering the different scanning positions of a reference measurement. The cross section results in a polyline, ready for further analysis in computer aided design (CAD) software. Based on the polyline of the cross section, radius values from the axis of the best-fit cylinder to the cross section polyline were 
determined every $0 \cdot 1$ grad and subsequently these radius values were smoothed by calculating the average within the interval of $0.5 \mathrm{grad}$ to the left and right of this radius.

To check for deviations caused by so-called 'ovalisation' of the tunnel walls, the smoothed radius values were compared to the design inner radius of $3.650 \mathrm{~m}$ and previous measurements of the same tunnel section. All calculated deviations from ovalisation are compared to the $95 \%$ confidence level, based on the experimental standard deviation determined by the authors $(0.4-0.5 \mathrm{~mm})$, to detect any significant changes.

Between (i) the previous measurements to obtain the above mentioned standard deviation and (ii) the measurements during the monitoring campaign described in this manuscript, part of the concrete rail bed was built and the tunnel surface was sprayed with a granular fire-protective layer (Figs 7 and 8). Under these measurement conditions, only one laser scanning setup is required to obtain full coverage of the tunnel section. To measure the influence of these changed tunnel conditions and surface material, experimental standard deviations were determined for these specific measurement conditions. The knowledge of the achievable standard deviations form an essential part in the correct interpretation of detected changes in ovalisation between low and high tide, allowing a conclusion of whether these changes are due to measurement error or due to actual deformation of the tunnel ring.

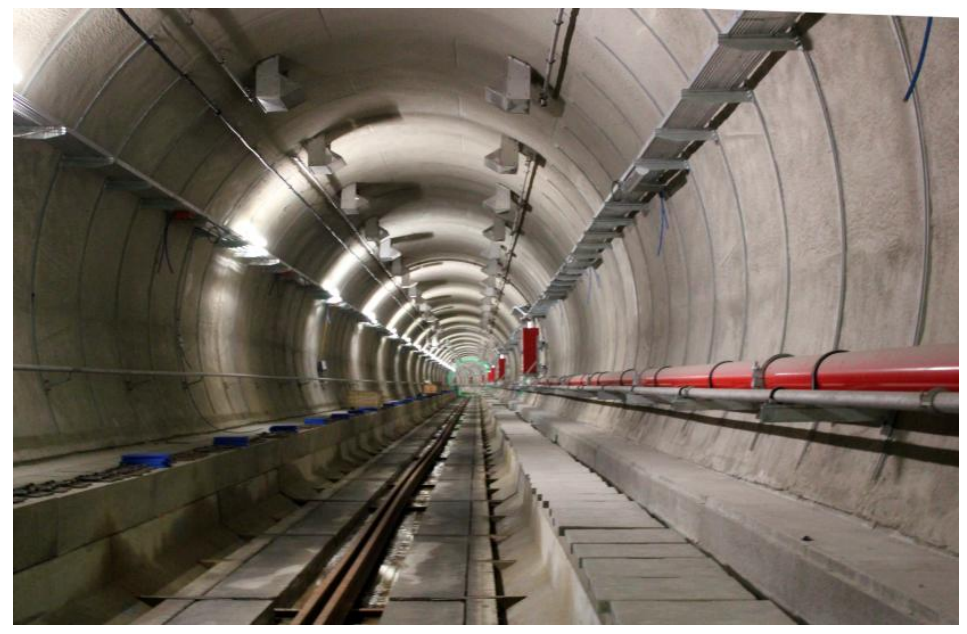

FIG. 7. Measurement conditions during the integrated monitoring with constructed rail bed and fire protective layer on the tunnel section

Within a timeframe of approximately 20 minutes, one of the tunnel sections was measured multiple times to calculate the experimental standard deviations, assuming that no significant deformations occurred during this short time span. First, the tunnel section was measured four times from the same scanning position and without any changes to the reference marker. This reference marker is a black-and-white target 
that indicates the exact location of the calculated cross-sections. It can be screwed onto a fixed bolt in the tunnel section every time a monitoring measurement has to be performed (Fig. 8).

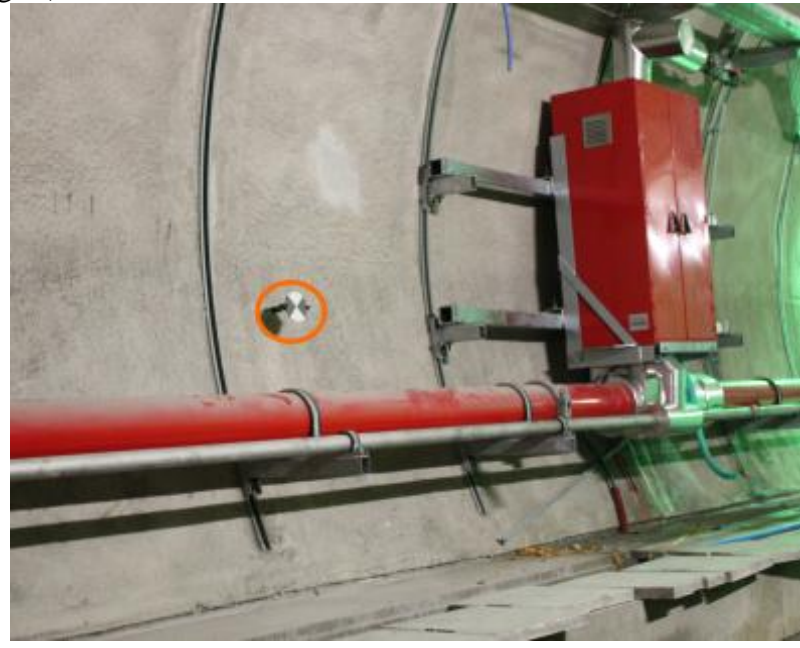

FIG. 8. Black-and-white reference marker (ringed) attached to the bolt in the tunnel surface.

Another series of four measurements was taken from a different scanning position for each measurement, simulating the measurements of the section on various points in time without any material setup point for the laser scanner. In this latter series, one reference marker was fixed during all four measurements (comparable to the first series). Another marker was replaced on a second bolt after each measurement, again simulating measurements on different points in time. The processing of these data results in three different standard deviations for the radius values of the cross-section, indicating the influence of a fixed or variable scanning position or target position. For the $[\mathrm{x}-0.5 \mathrm{grad}$; $\mathrm{x}+0.5 \mathrm{grad}]$ smoothing interval of the radius values, the standard deviations are $0.27 \mathrm{~mm}, 0.42 \mathrm{~mm}$ and $0.44 \mathrm{~mm}$ respectively for measurements: (i) from the same scanning setup; (ii) from different setups, and (iii) from different setups involving replacing the reference marker between each measurement.

If only the upper circular part of the tunnel section is taken into account, the experimentally based standard deviations of the radius values of the cross section are slightly higher than the previously determined standard deviations, due to the rough fire-protective layer on the concrete segments. However, these values still fall within the $0.5 \mathrm{~mm}$ requirements for these tunnel monitoring projects, as requested by the client. The lower part of the tunnel section, however, consists of a concrete rail bed and this area resulted in higher values $(0.60 \mathrm{~mm} ; 1.13 \mathrm{~mm} ; 1.05 \mathrm{~mm})$. This is mostly due to the extreme incidence angles on the pathway, the bottom part of the field of view of the laser scanner and the loose wooden beams, concrete tiles or mud on the rail bed which can easily have undergone small changes between the different measurements. Because the circular upper part of the tunnel section is the most 
relevant area of interest to monitor the deformations caused by the water level variations, the analysis will further focus on that part.

To monitor the tidal influences on the tunnel sections, the laser-scanning measurements at low and high tide were processed for each tunnel tube. As detailed below, there was no statistically significant difference between both measurements. To confirm these results, a measurement between low and high tide was also processed ('mid tide'). Because this measurement confirmed the previous results, there was no need to process any other measurements within the tidal cycle. Based on the project requirements of $0.5 \mathrm{~mm}$ accuracy $(\sigma)$, which was achieved by the experimental standard deviations, the significance level for the comparison between two measurements is set at $2 \sigma \sqrt{ } 2=1.4 \mathrm{~mm}$. Fig. 9 shows the difference between the measurement at low tide and the measurement at high tide of Tunnel North. This difference, represented by the black line (100 times exaggerated) and referenced to the design radius, clearly falls within the significance level boundaries (blue circles) in most places. Taking only the upper part of the section into account, the arithmetic mean difference (average of the differences) between both measurements is $0.0 \mathrm{~mm}$ and the absolute mean difference (the average of the absolute differences) is $0.3 \mathrm{~mm}$. If the lower part including the rail bed is also taken into account, the values are $0.1 \mathrm{~mm}$ for the mean difference and $0.5 \mathrm{~mm}$ for the absolute mean difference. 


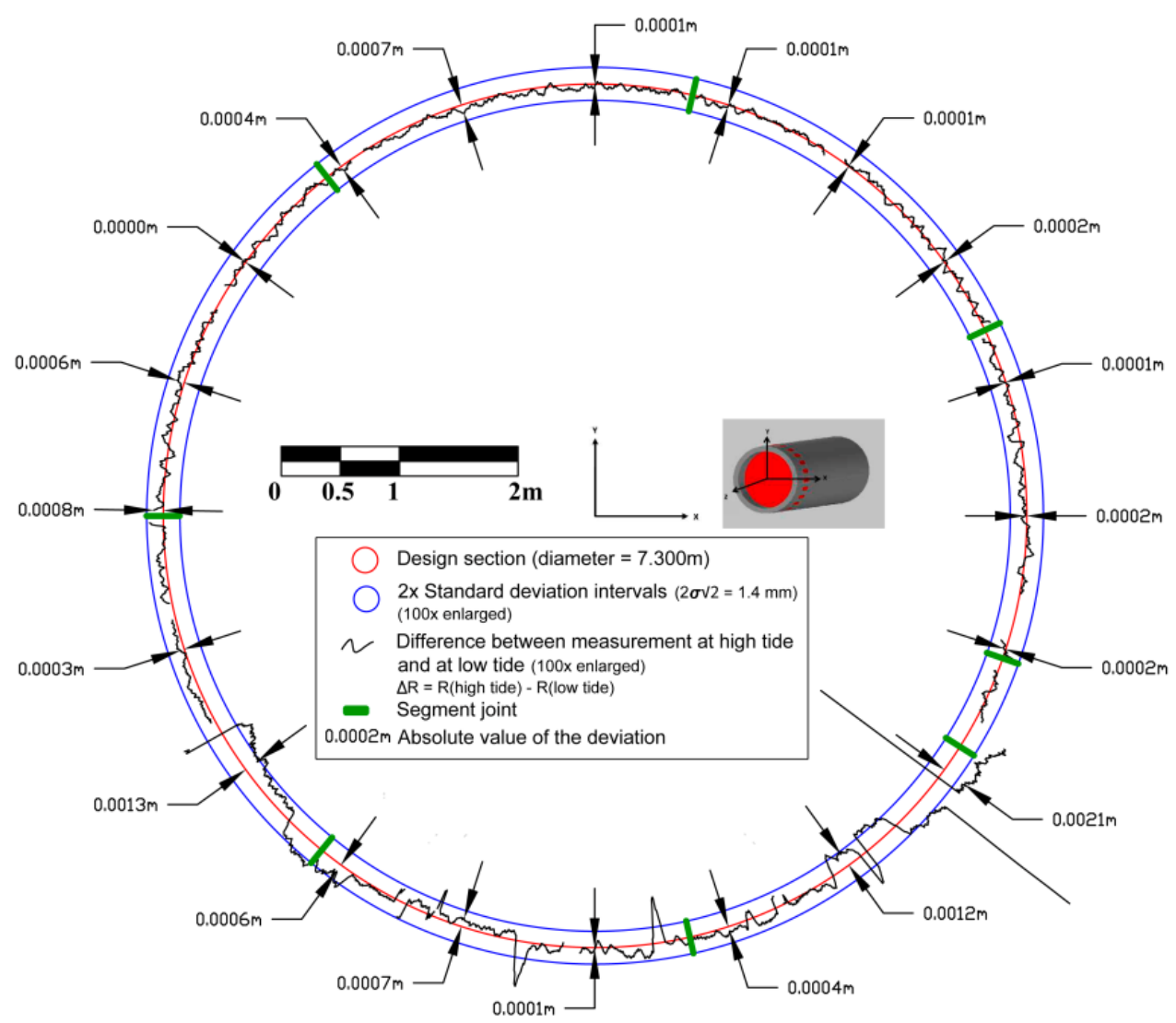

FIG. 9. Comparison between the measurement at low and high tide (Tunnel North); the differences in radius values between low and high tide are set out relative to the reference of the design radius.

Table 1 displays an overview of the mean differences for all processed measurements both in Tunnel North and Tunnel South. Differences between low and high tide, between the mid tide measurement and low tide, and between high tide and the mid tide measurement, fall well within the $95 \%$ significance interval $(2 \sigma \sqrt{ } 2)$. However, only the upper part of the tunnel section is included in these results. The significant differences that occur in the lower area of the tunnel section, as illustrated in Fig. 9, are caused by, amongst others, easy displacement of the concrete tiles on the side path and wooden beams, and the mud layer of the rail bed.

TABLE I. Averaged differences between two measurements for the monitored section in Tunnel North and Tunnel South (only the upper part of the tunnel sections).

\begin{tabular}{|c|c|c|c|c|}
\hline \multicolumn{5}{|c|}{ Differences $\Delta R$ between two measurements at different tides (only upper part of the tunnel section). } \\
\hline & \multicolumn{2}{|c|}{ Tunnel North } & \multicolumn{2}{|c|}{ Tunnel South } \\
\hline & $\operatorname{Mean}(\mathrm{mm})$ & $(\mathrm{mm})$ & $\operatorname{Mean}(\mathrm{mm})$ & $(\mathrm{mm})$ \\
\hline$\Delta \mathrm{R}=\mathrm{R}($ high tide $)-\mathrm{R}($ low tide $)$ & 0.0 & 0.3 & 0.1 & 0.6 \\
\hline
\end{tabular}




\begin{tabular}{c|cccc}
\hline$\Delta \mathrm{R}=\mathrm{R}($ mid tide) $-\mathrm{R}$ (low tide) & 0.4 & 0.5 & 0.0 & 0.4 \\
\hline$\Delta \mathrm{R}=\mathrm{R}$ (high tide) $-\mathrm{R}$ (mid tide) & -0.4 & 0.5 & 0.0 & 0.7 \\
\hline
\end{tabular}

\section{DISCUSSION}

The levelling measurements during extensive monitoring programme described above confirmed the earlier levelling results that the tunnel sections below the River Scheldt are influenced by the tidal fluctuations of the water level. The measurements of the levelling bolts indicated a difference in height between low and high tide of up to $10 \mathrm{~mm}$, measured from a fixed reference point outside the influence of the water level variations. The strain gauge measurements during the integrated monitoring show a difference in strains between low and high tide, also confirming that the tunnel structure undergoes a significant influence from the river tide. Based on the $10 \mathrm{~mm}$ height difference between low and high tide and the strain gauge results, the question remains whether this height difference is due to a deformation of the tunnel section itself or if the part of the tunnel below the River Scheldt experiences another vertical movement. A deformation of the tunnel section itself during each tide cycle, resulting in an eccentric 'egg' or 'pumpkin' shape, could hold significant risks for both the strength and durability of the tunnel.

Complementing these levelling and strain gauge results with highly detailed and accurate $3 \mathrm{D}$ laser scanning point clouds measured at successive stages of the tide cycle provides new insights into the actual deformation pattern of the tunnel structure. The cross sections derived from the laser scanning point clouds show, with very high accuracy, that there is no significant change in 'ovalisation' of the monitored tunnel section during the tide level variations. The combination of the results of the three different simultaneous measurement techniques points towards the conclusion that at least a part of the tunnel structure undergoes a vertical movement caused by the changing water pressure but that there is no deformation in the shape of the tunnel sections themselves, reducing the critical character of the deformation and actions to be undertaken. The research presented in this paper is based on monitoring one critical tunnel section located in an area with probably the largest tidal influences. As these results show no change in shape of the tunnel section, eliminating an important cause of the $10 \mathrm{~mm}$ height variation, other hypotheses about the cause of the height variations still exist and should be further investigated.

\section{CONCLUSIONS}

Laser scanning is more and more being applied as a measurement technique for large and complex infrastructural projects. In this research, the focus lies in the importance of laser scanning as part of an integrated monitoring programme, in combination with levelling and strain gauge measurements, for monitoring a recentlybuilt twin-tube tunnel complex influenced by river tides.

Due to the water level fluctuations of the River Scheldt, reaching a low and high tide value twice a day, a height difference of up to $10 \mathrm{~mm}$ for bolts installed in the tunnels was measured by levelling. Consequently, integrated monitoring was carried 
out combining levelling and strain-gauge measurements with laser-scanning measurements. A tunnel section in both tunnel tubes under the centre of the River Scheldt was measured using laser scanning every hour and on the specific low and high tide moments.

Simultaneous levelling and strain measurements were performed in one of the tunnel tubes ('Tunnel South'), confirming respectively a variation in the height of the bolts below the River Scheldt between the different measurement series and increase of the strains at low tide, indicating a general decrease of compression of the tunnel rings. Such deformations of the tunnel section itself during each tide cycle, resulting in an 'egg' or 'pumpkin' shape, could hold large risks for both the strength and durability of the tunnel. The laser scanning results, however, clearly show that there is no significant change in 'ovalisation' of the tunnel section during the tidal cycle. The combination of the three different measurement results leads to the conclusion that the tunnel below the River Scheldt undergoes a vertical movement during each tide cycle, but without deformation of the circular shape of the tunnel sections. However, despite the more thorough insights thanks to the combination of the different monitoring techniques, different hypotheses about this vertical movement remain. Possibly, the variable ground composition and local differences in compactness of the grouting around the tunnel structure have an influence on the water pressure around the tunnel tubes. The more thorough view on the deformation pattern, thanks to the integration of laser scanning measurements, improves the risk assessment of the deformations and changes the perspective of the possible long-term consequences.

Although this conclusion reduces the acute risk for the durability of the tunnel structure, further measurements are necessary to locate the points around both river banks where the tunnel structure changes from the situation where it is not influenced by the tidal water level variations. Moreover, further research will focus on investigating other possible causes for the tidal height variations by combining the different applied monitoring techniques and a detailed 3D analysis of the ground composition around the tunnel structure.

\section{REFERENCES}

Alba, M., Fregonese, L., Prandi, F., Scaioni, M. and VAlgoi, P., 2006. Structural monitoring of a large dam by terrestrial laser scanning. In Maas, H.-G. and Schneider, D. (Eds.), Proceedings of the ISPRS Commission V Symposium "Image Engineering and Vision Metrology", September 25-27, 2006, Dresden, Germany, ISPRS Archives - Volume XXXVI Part 5, 6 pages.

ArgüElles-Fraga, R., OrdoneZ, C., Garcia-Cortes, S. and RocA-PARdinas, J., 2013. Measurement planning for circular cross-section tunnels using terrestrial laser scanning. Automation in Construction, 31: 1-9. DOI: 10.1016/j.autcon.2012.11.023.

Bertacchini, E., Boni, E., CAPRA, A., CAstagnetti, C. and Dubbini, M., 2010. Terrestrial laser scanner for surveying and monitoring Middle Age towers. Proceedings of the XXIV FIG International Congress 2010 "Facing the Challenges - Building the Capacity", Sydney, Australia, 13 pages.

CABAllero, D., EstebAn, J. and IZQUIERDO, D. B., 2007. ORCHESTRA: a unified and open architecture for risk management applications. Geophysical Research Abstracts, $4^{\text {th }}$ EGU General Assembly, Vol. 9, 3 pages.

ChounTA, I. and IOANNIDIS, C., 2012. High accuracy deformation monitoring of a concrete beam using automatic photogrammetric techniques. Proceedings of the FIG Working Week 2012 - Knowing to manage the territory, protect the environment, evaluate the cultural heritage, Rome, Italy, 16 pages.

FuJINO, Y. and SiRINGORINGO, D. M., 2011. Bridge monitoring in Japan: the needs and strategies. Structure and Infrastructure Engineering, 7(7-8): 597-611. DOI: 10.1080/15732479.2010.498282. 
NUTTENS et al. Terrestrial laser scanning in the integrated monitoring of tidal influences on a concrete tunnel

HAN, J.-Y., GUO, J. and JIANG, Y.-S., 2013a. Monitoring tunnel profile by means of multi-epoch dispersed 3-D LiDAR point clouds. Tunnelling and Underground Space Technology, 33: 186-192. DOI: 10.1016/j.tust.2012.08.008.

HAN, J.-Y., GuO, J. and JiANG, Y.-S., 2013b. Monitoring tunnel deformations by means of multi-epoch dispersed 3D LiDAR point clouds: an improved approach. Tunnelling and Underground Space Technology, 38: 385-389. DOI: 10.1016/j.tust.2013.07.022.

KHOO, V. H. S., ToR, Y. K. and ONG, G., 2010. Monitoring of high rise building using real-time differential GPS. Proceedings of the XXIV FIG International Congress 2010 "Facing the Challenges - Building the Capacity", Sydney, Australia, 14 pages.

LAM, S. Y. W., 2006. Application of terrestrial laser scanning methodology in geometric tolerances analysis of tunnel structures. Tunnelling and Underground Space Technology, 21: 410. DOI: 10.1016/j.tust.2005.12.057.

Lerma Garcia, J. L., Van Genechten, B., Heine, E. and Santana Quintero, M., 2008. $3 D$ Risk Mapping. Theory and Practice on Terrestrial Laser Scanning. Training Material Based on Practical Applications. Universidad Politecnica de Valencia, Spain, hardcopy, 70 pages.

LichTI, D. D. and ChOW, J. C. K., 2013. Inner constraints for planar features. Photogrammetric Record, 28(141): 74-85. DOI: 10.1111/j.1477-9730.2012.00700.x

Lichti, D. D., STEwarT, M. P., TSAKIRI, M. and SNOW, A. J., 2000. Calibration and testing of a terrestrial laser scanner. Proceedings of the XIXth ISPRS Congress, Technical Commission V: Close-Range Techniques and Machine Vision, July 16-23, 2000, , Amsterdam, The Netherlands, ISPRS Archives Volume XXXIII Part B5 (/1-2), 485-492.

Lindenbergh, R., PfeIfer, N. and Rabbani, T., 2005. Accuracy analysis of the Leica HDS3000 and feasibility of tunnel deformation monitoring. Proceedings of the ISPRS Workshop Laser Scanning 2005, WG III/3-4, V/3 , September 12-14, 2005, Enschede, The Netherlands, ISPRS Archives Volume XXXVI-3/W19, 24-29.

NEEDHAM, J. and DASH, B., 2012. Dynamic deformation monitoring of a transmission tower undergoing failure test by close range terrestrial photogrammetry. Proceedings of the FIG Working Week 2012 Knowing to manage the territory, protect the environment, evaluate the cultural heritage, Rome, Italy, 19 pages.

Nuttens, T., Stal, C., De Backer, H., Schotte, K., Van Bogaert, P. and De Wulf, A., 2014a. Assessment of the tidal influences on tunnels based on different monitoring techniques: laser scanning, levelling and strain gauges. In Kopàcik, A., Kyrinovic, P. and Stroner, M. (Eds.), Proceedings of the $6^{\text {th }}$ International Conference on Engineering Surveying INGEO 2014, April 3-4, 2014, Prague, Czech Republic, hardcopy, 223-228.

Nuttens, T., Stal, C., De backer, H., Schotte, K., Van Bogaert, P. and De Wulf, A., 2014b. Methodology for the ovalization monitoring of newly built circular train tunnels based on laser scanning: Liefkenshoek Rail Link (Belgium). Automation in Construction, 43: 1-9. DOI: 10.1016/j.autcon.2014.02.017.

Peeters, B., Couvreur, G., Razinkov, O., Kündig, C., Van der Auweraer, H. and De Roeck, G., 2009. Continuous monitoring of the Oresund Bridge: system and data analysis. Structure and Infrastructure Engineering, 5(5): 395-405. DOI: 10.1080/15732470701478362.

PEJIC, M., 2013. Design and optimisation of laser scanning for tunnels geometry inspection. Tunnelling and Underground Space Technology, 37: 199-206. DOI: 10.1016/j.tust.2013.04.004.

PFEIFER, N. and BRIESE, C., 2007. Laser scanning - principles and applications. Geo-Sibir, Nowosibirsk, III International Scientific Confernece, pp. 93 - 112,.

Psimoulis, P. A. and STIROS, S. C., 2007. Measurement of deflections and of oscillation frequencies of engineering structures using robotic theodolites (RTS). Engineering Structures, 29: 3312-3324. DOI: 10.1016/j.engstruct.2007.09.006.

Remondino, F., Rizzi, A., Barazzetti, L., Scaioni, M., Fassi, F., Brumana, R. and Pelagotti, A., 2011. Review of geometric and radiometric analyses of paintings. Photogrammetric Record, 26(136): 439-461. DOI: $10.1111 / j .1477-9730.2011 .00664 . x$.

RoCA-PARDiÑAS, J., ORDÓÑEZ, C., GARCIA-CORTÉS, S. and BELlo, A. Validating the supporting structure of a parabolic solar collector using close range photogrammetry. Photogrammetric Record, 28(142): 211-226.

Rönnholm, P., Nuikka, M., Suominen, A., Salo, P., Hyyppä, H., Pöntinen, P., Haggrén, H., Vermeer, M., Puttonen, J., HiRsi, H., KuKKo, A., KaARTinen, H., HyypPä, J. and JaAkKola, A., 2009. Comparison of measurement techniques and static theory applied to concrete beam deformation. Photogrammetric Record, 24(128): 351-371. 
Schotte, K., De Backer, H., Nuttens, T., De Wulf, A. and Van Bogaert, P., 2013a. Strain gauge measurements of the precast concrete lining of a shield-driven tunnel. Insight, 55(2): 88-95, doi: 10.1784/insi.2012.55.2.88

Schotte, K., De Backer, H., Nuttens, T., De Wulf, A. and Van Bogaert, P., 2013b. Verification of the performance of the precast concrete lining in the Diabolo Tunnel and Liefkenshoek rail tunnel. Proceedings of the IABSE Conference: "Assessment, upgrading and refurbishment of Infrastructures", Rotterdam, The Netherlands, 8 pages.

Schotte, K., De Backer, H., Van Bogaert, P., Nuttens, T. and De Wulf, A., 2014. Design considerations of segmental tunnel linings in assembly stage. Proceedings of the World Tunnel Congress 2014 - "Tunnels for a better life", Foz do Iguacu, Brazil, page 30.

Thomas, G. and IsAacs, R., 2011. Basic principles of lasers. Anaesthesia and Intensive Care Medicine, 12(12): 574-577.

TUC RAIL, 2010. Antwerp: The tunnel borers for the Liefkenshoek rail tunnel. TUC RAIL - Belgian Rail Engineering. 2 pages.

http://www.tucrail.be/EN/media/Documents/Anvers_Liefkenshoek_boring\%5Bhomepage\%5D_EN.pd f (Accessed 3rd September 2014)

Van Bogaert, P., 2009. Recent and future railway tunnels in Belgium. Proceedings of the ITA World Tunnel Conference "Safe Tunnelling for the City and the Environment", Budapest, Hungary. Pages 689-690.

VAn Gosliga, R., Lindenbergh, R. and PFeIFeR, N., 2006. Deformation analysis of a bored tunnel by mean of terrestrial laser scanning. In Maas, H.-G. and Schneider, D. (Eds.), Proceedings of the ISPRS Commission V Symposium "Image Engineering and Vision Metrology", September 25-27, 2006, Dresden, Germany, ISPRS Archives - Volume XXXVI Part 5, 6 pages.

Yoon, J.-S., SAGONG, M., LEE, J. S. and LeE, K., 2009. Feature extraction of a concrete tunnel liner from 3D laser scanning data. NDT\&E International, 42: 97-105. DOI: 10.1016/j/ndteint.2008.10.001.

ZOGG, H.-M. and INGENSAND, H., 2008. Terrestrial laser scanning for deformation monitoring - load tests on the Felsenau Viaduct (CH). In Chen, J., Jiang, J., Maas, H.-G. (Eds.), Proceedings of the XXIst ISPRS Congress, Technical Commission 5: "Silk Road for Information from Imagery", July 3-11, 2008, Beijing, China, ISPRS Archives - Volume XXXVII Part B5, 555-562. 